\title{
Ecological model links proto-oncogene to high incidence of metastatic cancers in African-Americans
}

Constance Hilliard, $\mathrm{PhD}^{1, *}$

1 Department of History, University of North Texas, Denton, TX 76203, USA

\begin{abstract}
Cancers identified by the uncontrolled proliferation of the TRPV6 mRNA biomarker, kill African-Americans (AAs) at nearly twice the rate of Whites. Malignancies assigned to this class include: Metastatic prostate cancer, triple negative breast cancer, colorectal and multiple myeloma. This ecological model identifies the cause as an ethnic-specific haplotype of the TRPV6 calcium ion channel, which is also protooncogenic. This ancestral TRPV6a variant has been shown in several studies to be more calcium absorbent than the non-African/European TRPV6b allele. AAs inherited strong bones from their low-calcium consuming (200-400 mg/day) Niger-Kordofanian West African ancestors. However, AAs are maladapted to the high calcium (1,000+ mg/day) food environment of the U.S. As a consequence, the ancestral TRPV6a allele can become invasively oncogenic when over-exposed to excess free calcium ions, leading to the aforementioned class of cancers.
\end{abstract}

Keywords: ecological model; proto-oncogene; metastatic cancers; African-Americans

\section{Hypothesis}

The unusually high mortality rate of African-Americans from an aggressive sub-type of cancers that are generally fatal, is triggered by the $\mathrm{Ca}^{2+}$ hypersensitivity of the ancestral TRPV6a proto-oncogene.

\section{Introduction}

Medical researchers have long noted that Americans of African descent have a lower incidence than Whites for such common malignancies as luminal A breast cancer (Estrogen receptor-positive; HER2 receptor-negative), Non-Hodgkin lymphoma and melanoma, while having nearly twice the mortality rate for certain more aggressive cancers. This ecological model identifies the underlying reasons for this pattern of cancer susceptibility. In doing so, it offers a therapeutic target for those cancers, which at the present time, carry a low prognosis because of the absence of targeted therapies for these tumor types [1].

\section{The TRPV6a proto-oncogene}

Metastatic prostate cancer ( $\mathrm{mPCa}$ ), triple negative breast cancer, colorectal and multiple myeloma cancers present different histologies and pathways. But, they are all characterized by the upregulation of TRPV6 calcium ion channel transcript and are generally incurable. The human TRPV6 gene is a calcium ion channel, which plays a key role in calcium homeostasis and mediates $\mathrm{Ca}^{2+}$ uptake in the intestine. It is located on chromosome 7q33-q34 in close proximity to the TRPV5 on 7q35. While nearly undetectable in normal prostate, mammary and other tissues, it becomes overexpressed in cancer tumorigenesis, initiating cell growth, proliferation and metastases. In breast tissue, TRPV6 mRNA expression is upregulated from 2 to 15 times the amount found in normal breast tissue. Recent studies have found such a strong connection, that they have suggested that the levels of TRPV 6 mRNA be used as a biomarker for metastatic prostate and colorectal cancer [2]. In the case of multiple myeloma, a strong TRPV6 expression has been found in the bone marrow [3].

Studies have identified two functional variants for the human TRPV6 gene. The African or ancestral TRPV6a variant (accession number: AJ243500) has been shown to be more calcium absorbent than the non-African TRPV6b

*Corresponding author: Constance Hilliard, Ph.D., Department of History, University of North Texas, Denton, TX 76203, USA. Email: constance. hilliard@unt.edu

Received 18 July 2018 Revised 22 August 2018 Accepted 27 August 2018 Published 3 September 2018

Citation: Hilliard C. Ecological model links proto-oncogene to high incidence of metastatic cancers in African-Americans. J Cancer Res Ther. 2018; 6(5):3740. DOI: 10.14312/2052-4994.2018-6

Copyright: (c) 2018 Hilliard C. Published by NobleResearch Publishers. This is an open-access article distributed under the terms of the Creative Commons Attribution License, which permits unrestricted use, distribution and reproduction in any medium, provided the original author and source are credited. 
variant (AJ243501) carried by Europeans, Asians and those Latin Americans, who are not of African descent [4]. This may explain, in part, the reason for AAs having strong bone mineral density, even while being labelled "calcium deficient" by federal U.S. nutritional standards. Even though $75 \%$ of AAs are lactase non-persistent (lactose intolerant), this group still consumes $400 \%$ more dietary calcium than its Niger-Kordofanian (NK) West African ancestors. A critical factor that has until now been overlooked is the fact that West Africans are virtually immune to osteoporosis even though their calcium consumption is only $200-400 \mathrm{mg} /$ day [5]. The calcium homeostatic mechanism is more efficient in this population on account of the TRPV6a variant working in synch with the A563T African variant of the TRPV5 gene, which functions to retain calcium in the body rather than expelling excess amounts in the urine [6]. However, a benefit in low-calcium consuming West Africa, becomes maladaptive in America's high calcium dairy-food environment.

Because so few genome sequencing studies have been performed on African populations, the distribution of the ancestral and derived TRPV6 alleles are not yet known among Cushitic, Nilo-Saharan and other non-NigerKordofanian populations, which inhabit that continent.

\section{Statistical analysis}

AAs have a higher death rate for cancer (189.8 per $100,000)$ than Whites (163.8 per 100,000$)$, according to statistics published by the Centers for Disease Control and Prevention [7]. This is not surprising given socio-economic factors that reduce medical insurance availability and thus prevents the early diagnosis of cancers. And yet, if mortality statistics for AAs and Whites are compared for non-TRPV6expressing cancers, the aforementioned ethnic health disparity disappears. That is, AAs (Black) death rates from TRPV6-expressing cancers are 1.67 times that of Whites. However, that ratio shrinks to near parity at 1.05 when the 10 most common non-TRPV6 cancers are compared between the two ethnicities (Table 1). Recognizing the importance of this aggressive cancer sub-type for AAs becomes critical in devising health care strategies that lessen the disparity between demographic populations.

\section{Why has this proto-oncogene been missed until now?}

Over the past decade, 75 genomic locations have been identified in Genome-Wide Association Studies (GWAS) that might be associated with mPCa risk and account for the Black/White disparity in this cancer type [8]. But so far, none of the identified single nucleotide polymorphisms (SNPs) have proven to be causative. The reasons for this failure may relate to the fact that Africans possess approximately 10 million SNPs, while Asians and Europeans carry half as many [9]. And yet according to a 2016 meta-analysis published in Nature, only 3\% of GWAS research has been performed on Africans [10]. As a consequence, many SNPS found in AAs but not in Whites are labeled "variants of unknown significance" or VUS [11]. This ecological model is able to narrow the search for causative polymorphisms by examining the behavioral patterns and environmental conditions of the populations being researched, rather than just their genomic signature.
Table 1 Comparison of cancer death rates by race/ethnicity*.

Death rates for the 10 most common, Non-TRPV6-expressing cancers (Per 100,000)

\begin{tabular}{|c|c|c|c|}
\hline Whites, 2011-2015 & $\begin{array}{l}\text { Both } \\
\text { sexes }\end{array}$ & $\begin{array}{c}\text { African-Americans, } \\
\text { 2011-2015 }\end{array}$ & $\begin{array}{l}\text { Both } \\
\text { sexes }\end{array}$ \\
\hline All Sites & 94.5 & & 98.9 \\
\hline Lung \& Bronchus & 44.1 & Lung \& Bronchus & 46.2 \\
\hline Pancreas & 10.8 & Pancreas & 13.3 \\
\hline Leukemia & 6.9 & $\begin{array}{l}\text { Liver \& Intrahepatic } \\
\text { bile duct }\end{array}$ & 8.3 \\
\hline $\begin{array}{l}\text { Non-Hodgkin } \\
\text { lymphoma }\end{array}$ & 6.0 & Stomach & 5.7 \\
\hline $\begin{array}{l}\text { Liver \& Intrahepatic } \\
\text { bile duct }\end{array}$ & 6.0 & Leukemia & 5.6 \\
\hline $\begin{array}{l}\text { Brain \& Other nervous } \\
\text { system }\end{array}$ & 4.8 & Corpus \& Uterus & 4.9 \\
\hline Urinary bladder & 4.6 & $\begin{array}{l}\text { Non-Hodgkin } \\
\text { lymphoma }\end{array}$ & 4.2 \\
\hline Esophagus & 4.3 & Kidney \& Renal pelvis & 3.7 \\
\hline Kidney \& Renal pelvis & 4.0 & Urinary bladder & 3.5 \\
\hline Melanoma of the skin & 3.0 & Esophagus & 3.5 \\
\hline \multicolumn{4}{|c|}{$\begin{array}{l}\text { Death rates for the } 4 \text { most common, TRPV6-expressing cancers (Per } \\
100,000)\end{array}$} \\
\hline All Sites & 27.6 & & 46.2 \\
\hline Colon \& Rectum & 14.1 & Colon \& Rectum & 19.4 \\
\hline Prostate & 7.4 & Prostate & 14.6 \\
\hline Myeloma & 3.1 & Myeloma & 6.2 \\
\hline $\begin{array}{l}\text { Triple negative breast } \\
\text { [25] }\end{array}$ & 3.0 & Triple negative breast & 6.0 \\
\hline
\end{tabular}

*US Mortality Files, National Center for Health Statistics, Center for Disease Control and Prevention. Data taken from Table 1.27 [7].

In 2009, an article appeared in BMC Cancer entitled: "TRPV6 alleles do not influence prostate cancer progression." While the study mentioned the fact that AAs have a higher risk of prostate cancer ( $\mathrm{PCa}$ ), the subjects participating in the study were 169 healthy Caucasians, none of whom carried the TRPV6a African genotype. These subjects were compared with 142 tissue samples of prostatic adenocarcinoma. Eighty-eight percent (125) of the tissue samples exhibited the non-African TRPV6b/b genotype, $11.3 \%$ (16) the heterozygous b/a genotype and only one sample $(0.7 \%)$ was homozygous for $a / a$. The researchers concluded from the comparison of the two datasets that: "the TRPV6 genotype does not correlate with the progression of prostatic adenocarcinoma" [12]. However, the exclusion of African descent subjects and the lack of tissue samples with the African TRPV6a variant undercuts the certainty expressed in the study's conclusion.

\section{The calcium conundrum}

Calcium is the most abundant mineral in the human body, $99 \%$ of which goes to maintain bone health. The remaining $1 \%$ is tightly regulated, contributing to such vital body functions as blood clotting, cardiac and other muscle contractions as well as cell apoptosis. But it has 
also been implicated in cell proliferation and metastasis. In fact, a growing number of studies have linked the overconsumption of calcium to PCa [13-15]. However this association between cancer and calcium has not been fully pursued as regards AAs, who consume 30\% less of the mineral than their White counterparts, but suffer a 200\% higher mortality rate from the disease.

Progress in understanding AAs higher susceptibility to metastatic cancers has been impeded by a medical paradigm that universalizes calcium homeostasis based on the nutritional needs of European populations. The daily recommended dietary calcium intake of 1000-1200 mg. overlooks the fact that African populations who maintain strong bone health on 200-600 mg/calcium may face deleterious consequences from chronic calcium consumption above their particular biological setpoint (Figure 1). For example, AAs are an admixed population generally composed of $75 \%$ Niger-Kordofanian West African genetic ancestry and 25\% Northern European. A more accurate formula for this group's calcium intake would calculate their ancestral (200-400 mg) and European calcium needs as a function of ratios of genetic ancestry: (.75) $400+(.25) 1000=550 \mathrm{mg}$.

\section{Ethnic differences in calcium homeostasis puts African-American males at higher risk of excess $\mathrm{Ca}^{2+}$ flooding of prostatic tissue \& mutagenesis}

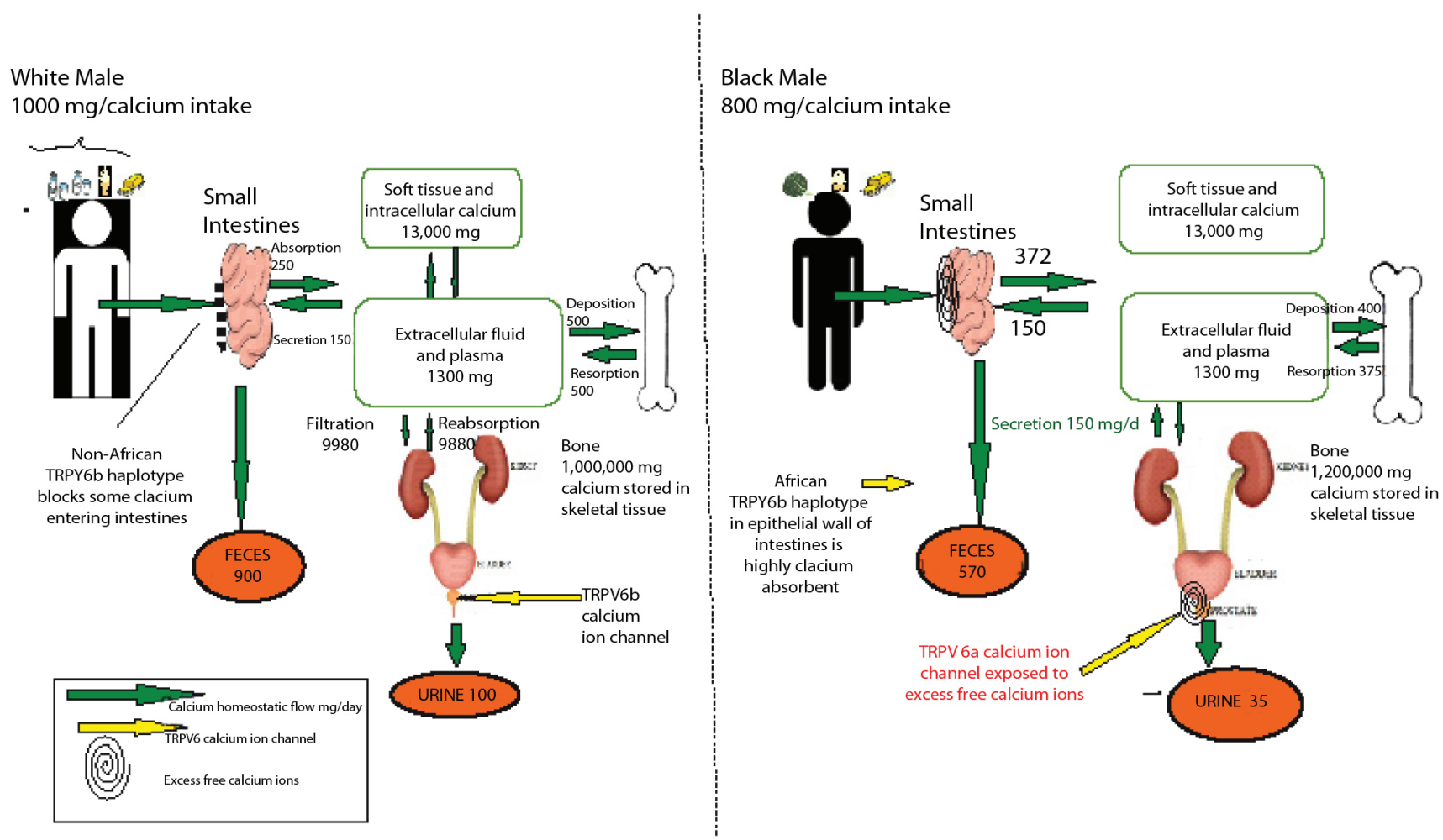

Figure 1 This graphic shows that a White male's $1000 \mathrm{mg}$. calcium intake will result in homeostatic balance, with the expulsion of excess calcium through the urine and feces. However, African-American male who consumes $200 \mathrm{mg}$. less may still have a remaining excess of nearly 200 mg. calcium because less will be expelled in the urine and feces. The excess free calcium ions may cause carcinogenesis in the prostatic tissue.

This estimated $550 \mathrm{mg} /$ day of dietary calcium intake for AAs is nearly half that of Europeans. But at the present time, American AAs consume approximately $800+\mathrm{mg} /$ calcium [16]. Although lactase non-persistent, this ethnic population inhabits a food culture in which low-lactose (but high calcium) dairy products such as ice cream, yogurt, cheeses and butter are available to them. At the present time, health care professionals encourage this ethnic group to consume more of the mineral because they are defined as calcium deficient by USDA standards.

\section{Calcium and TRPV6-expressing cancers}

The rate of osteoporosis in American White women is twice that of AAs females. And yet, the nutritional message conveyed by public health officials is that all women consume higher levels of calcium in order to ward off fragile bone disorders. As a consequence, breakfast cereals, orange juice, vitamin supplements and even nonfood products such as face creams and cosmetics are marketed to women with calcium supplementation.

However, the role dietary calcium plays in triggering TRPV6-expressing breast carcinogenesis in AAs has been complicated by methodological flaws. A 2009 study, involving a cohort of 61,433 Swedish women, was published in the The American Journal of Clinical Nutrition. It saw no correlation between dietary calcium intake and breast cancer [17]. However, this research did not caution that the findings for a Northern European genetic population might not be universal for all human groups. 
This is especially the case for populations who carry the more calcium absorbent ancestral TRPV6a variant.

A 2013 study looked specifically at AAs women and dietary calcium intake and also found no link to breast cancer. That study using data from the Black Women's Health Study of 1,268 incident breast cancer cases identified among 52,062 women appeared to offer a comprehensive examination of the calcium-breast cancer association within this ethnic population [18]. It noted without emphasis that 24 to $80 \%$ of AAs women exhibited signs of lactase non-persistence (lactose intolerance). In downplaying the implications of this genomic difference, it overlooked the fact that the only AA women drinking milk would be those with the least amount of West African (99\% lactose intolerant) ancestry.

The subject of possible links of dietary calcium to PCa has been more thoroughly researched and more definitive. A growing number of studies have linked the overconsumption of calcium to mPCa [19]. A 2012 report authored by Schwartz and Skinner found an association between total and ionized serum calcium and PCa death for the first 96 months of the disease [20]. In another study the same year, Rowland and Schwartz [21] also identified calcium intake as a risk factor for AA males with PCa. More recent studies have looked at ionized calcium at the cellular level and shown that a chronic excess can lead to irritations in the organelles, including the initiation of nuclear DNA mutations [22]. The greater the exposure of the TRPV6 intestinal channel to $\mathrm{Ca}^{2+}$ (in the absence of alleles blocking its intestinal absorption), the higher the risk of producing mutagenic changes in the prostatic TRPV6 calcium ion channel.

\section{Conclusions}

The African TRPV6a calcium ion channel variant is more absorbent and retentive of $\mathrm{Ca}^{2+}$ than its TRPV6b non-African counterpart. As a consequence, carriers of the ancestral TRPV6a variant are at increased risk of mPCa, triple negative breast cancer and multiple myeloma. Because the biomarker for these cancers is the upregulation of TRPV6 transcript, that calcium ion channel becomes a therapeutic target for intervention.

At the present time, researchers at Chongqing Medical University in China have achieved some measure of success applying a non-anesthetic use for lidocaine to inhibit the proliferation of TRPV6-expressing cancer cells [23]. Also, soricidin, a peptide derived from the venom of the short tailed shrew, has been made into a TRPV6 inhibiting drug, SOR-C13. It is undergoing phase II testing for its efficacy in the treatment of solid tumors [24].

\section{Acknowledgements}

I am grateful for the support of colleagues in the History Department at the University of North Texas (UNT), and most especially for the time and insights provided so generously by UNT biologist, Dr. Denise Simmons.

\section{Conflicts of interest}

Author declares no conflicts of interest.

\section{References}

[1] DeSantis CE, Siegel RL, Sauer AG, Miller KD, Fedewa SA, et al. Cancer statistics for African Americans, 2016: Progress and opportunities in reducing racial disparities. CA Cancer J Clin. 2016; 66(4):290-308.

[2] Lehen'kyi V, Raphaël M, Prevarskaya N. The role of the TRPV6 channel in cancer. J Physiol. 2012; 590(6):1369-1376.

[3] Bong AHL, Monteith GR. Calcium signaling and the therapeutic targeting of cancer cells. Biochim Biophys Acta. 2018; S0167-4889(18):3010330104.

[4] Hughes DA, Tang K, Stromtmann R, Schoneberg T, Prenen J, et al. Parallel selection on TRPV6 in human populations. PLoS One. 2008; 3(2):e1686.

[5] Hilliard, CB. High osteoporosis risk among East Africans linked to lactase persistence genotype. Bonekey Rep. 2016; 5:803.

[6] Na T, Zhang W, Jiang Y, Liang Y, Ma HP, et al. The A563T variation of the renal epithelial calcium channel TRPV5 among African Americans enhances calcium influx. Am J Physiol Renal Physiol. 2009; 296(5):F1042F1051.

[7] US Mortality Files, National Center for Health Statistics, Center for Disease Control and Prevention. https://seer.cancer.gov/archive/ csr/1975_2011/browse_csr.php?sectionSEL=1\&pageSEL=sect_01 _table. 27

[8] Hsing AW, Yeboah E, Biritwum R, Tettey $Y$, De Marzo AM, et al. High prevalence of screen detected prostate cancer in West Africans: Implications for racial disparity of prostate cancer. J Urol. 2014; 192(3):730-735

[9] The 1000 Genomes Project Consortium, Abecasis GR, Altshuler D, Auton A, Brooks LD, et al. A map of human genome variation from population-scale sequencing. Nature. 2010; 467(7319):1061-1073.

[10] Popejoy AB, Fullerton SM. Genomics if failing on diversity. Nature. 2016; 538(7624):161-164.

[11] Ioannidis NM, Rothstein JH, PejaverV, Middha S, McDonnell, SK, et al. REVEL: An ensemble method for predicting the pathogenicity of rare missense variants. Am J Hum Genet. 2016; 99(4):877-885.

[12] Kessler T, Wissenbach U, Grobholz R, FlockerziV. TRPV6 alleles do not influence prostate cancer progression. BMC Cancer. 2009; 9:380.

[13] Chan JM, Stampfer MJ, Ma J, Gann PH, Gaziano JM, et al. Dairy products, calcium, and prostate cancer risk in the Physicians Health Study. Am J Clin Nutr. 2001; 74(4):549-554.

[14] Giovannucci EL, Rimm EB, Wolk A, Ascherio A, Stampfer MJ, et al. Calcium and fructose intake in relation to risk of prostate cancer. Cancer Res. 1998; 58(3):442-447.

[15] Rodriguez C, McCullough ML, Mondul AM, Jacobs EJ, FakhrabadiShokoohi D, et al. Calcium, dairy products, and risk of prostate cancer in a prospective cohort of United States men. Cancer Epidemiol Biomarkers Prev. 2003; 12(7):597-603.

[16] Hoy MK, Goldman JD. Calcium intake of the U.S. population. What we eat in America, NHANES 2009-2010. (Accessed June 2018) https:// www.ars.usda.gov/ARSUserFiles/80400530/pdf/DBrief/13_calcium_ intake_0910.pdf

[17] Larsson SC, Bergkvist L, Wolk A. Long-term dietary calcium intake and breast cancer risk in a prospective cohort of women. Am J Clin Nutr. 2009; 89(1):277-282.

[18] Genkinger JM, Makambi KH, Palmer JR, Rosenberg L, Adams-Campbell LL. Consumption of dairy and meat in relation to breast cancer risk in the Black Women's Health Study. Cancer Causes Control. 2013; 24(4):675-684.

[19] Song Y, Chavarro JE, Cao Y, Qiu W, Mucci L, et al. Whole milk intake is associated with prostate cancer-specific mortality among U.S. male physicians. J Nutr. 2013; 143(2):189-196.

[20] Schwartz GG, Skinner HG. A prospective study of total and ionized serum calcium and time to fatal prostate cancer. Cancer Epidemiol Biomarkers Prev. 2012; 21(10):1768-1773.

[21] Rowland GW, Schwartz GG, John EM, Ingles SA. Calcium intake and prostate cancer among African Americans: Effect modification by vitamin $D$ receptor calcium absorption genotype. J Bone Miner Res. 2012; 27(1):187-194.

[22] KadioB, Yaya S, Basak A, Djè K, Gomes J, et al. Calcium role in human carcinogenesis: a comprehensive analysis and critical review of literature. Cancer Metastasis Rev. 2016; 35(3):391-411.

[23] Jiang Y, Gou H, Zhu J, Tian S, Yu L. Lidocaine inhibits the invasion and migration of TRPV6-expressing cancer cells by TRPV6 downregulation. Oncol Lett. 2016; 12(2):1164-1170.

[24] Bowen CV, DeBay D, Ewart HS, Gallant P, Gormley S, et al. In vivo detection of human TRPV6-rich tumors with anti-cancer peptides derived from soricidin. PLoS One. 2013; 8(3): e58866.

[25] Amirikia KC, Mills P, Bush J, Newman L. Higher population-based incidence rates of triple-negative breast cancer among young African-American women: Implications for breast cancer screening recommendations. Cancer. 2011; 117(12):2747-2753. 